\title{
Ethics Across the Curriculum: An Effective Response to ABET 2000
}

\author{
William J. Frey, Halley D. Sanchez, and José A. Cruz \\ University of Puerto Rico at Mayagüez
}

\section{Introduction}

ABET 2000 challenges the traditional engineering curriculum by putting forward innovative general criteria to which any engineering program must respond. Engineering programs answer the challenge by developing objectives and measurable outcomes that represent locally generated instantiations of these criteria. Rather than elicit self-evaluations that merely tabulate activities designed to respond to surface criteria (bean-counting efforts), ABET obliges engineering schools to develop procedures to assess success in meeting these locally generated objectives and requires that they show that they have implemented a continuous process of self-improvement.

ABET has also made it clear that engineering programs must take engineering ethics seriously. The argument that engineers only make technical decisions, that they can (or should) delegate ethical responsibility to others (management, directors, government) no longer holds weight. It has been shown, for example, that the decisions an engineer makes when designing (such as trade off decisions) have strong ethical implications. ${ }^{1}$ Hence, an essential component of a successful program in engineering requires that students understand their professional and ethical responsibilities. ABET also asks programs to ensure that students integrate ethical considerations into a "major design project." Even a quick look at these ethics requirements makes it clear that the ethical component of this new engineering curriculum cannot be completely delegated to the ethics expert, for example, a philosopher who would teach a freestanding course in engineering ethics required of all engineering students. For reasons that we will discuss below, the freestanding course, while an essential part of a successful engineering program, does not by itself achieve the integration of ethics into the engineering curriculum that ABET requires.

One of the leading trends in ethics pedagogy today is to have ethical components or modules incorporated into actual professional or occupational courses to supplement a freestanding ethics course. This is known as Ethics Across the Curriculum (EAC), a holistic and interdisciplinary approach to integrating ethical concerns throughout the university academic program. It is holistic because it coordinates a series of exercises integrated into ordinary technical classes, and interdisciplinary because it relies on faculty from all university programs, including — but not limited to-engineering.

We will argue that EAC provides the best response to ABET 2000 ethics requirements because it integrates ethical concerns into ordinary technical courses and shows how ethical issues are embedded in professional judgment, decision-making, and designing. In the following, we will discuss why EAC poses an effective strategy for complying with ABET 2000 and summarize three workshops we held last year at the University of Puerto Rico at Mayaguiez. These workshops (originally motivated through a UPR central administration grant) introduced this 
approach to our Engineering school which is in the process of preparing for their ABET accreditation visit.

\section{How EAC contributes to ABET 2000 Compliance}

Ethics enters into the ABET 2000 accreditation process particularly in criterion $3 \mathrm{f}$ and $3 \mathrm{~h}$ of the widely discussed a-k criteria of outcomes and assessment for all engineering programs. These state that all engineering graduates must have:

- $\quad$ an understanding of professional and ethical responsibility (3f)

- the broad education necessary to understand the impact of engineering solutions in a global and societal context (3h).

Ethical considerations are also relevant to criterion 4, which states that all engineering students should have a "major design experience"...

based on the knowledge and skills acquired in earlier coursework and incorporating engineering standards and realistic constraints that include most of the following considerations: economic; environmental; sustainability; manufacturability; ethical; health and safety; social; and political. (emphasis added)

EAC has several features that make it an effective response to ABET 2000:

\section{It presents students with a more unified and integrated curriculum.}

One of the problems of outsourcing ethics to, say, the philosophy department is that students come away with the impression that ethics is not an integral part of engineering practice. Because their exposure is outside the mainstream engineering curriculum, they conclude that ethical problems do not occur in real world practice. (If it really were integral to practice, wouldn't their engineering instructors deem it important enough to introduce it into their classes?) EAC, on the other hand, shows students how ethical issues arise in day-to-day engineering practice. When students see that the engineering faculty is so committed to ethics that they include it in ordinary technical courses, then students will revaluate the importance of ethics, giving it more priority. Hence, engineering faculty who teach ethics in their classes provide effective role models; they mentor their students by sharing with them their concern about ethical issues that arise in engineering practice. Students will realize that making ethical decisions is an essential part of engineering work. They will also come to see that they cannot delegate ethical decisions to the personnel department, the corporate ethics expert (if there is one), the legal department, or the government.

2. EAC need not crowd out other course content because the use of ethics cases can actually help to teach complex and abstract engineering concepts.

An ethicist and an engineer found that the $\mathrm{NSPE}^{2}$ ethics video, Gilbane Gold, can be used to teach engineering concepts and methods. ${ }^{3}$ In their article, Pritchard and Holtzapple provide exercises that have students compare and evaluate three treatment solutions to the water contamination problem raised by the video: dilution by water, ion exchange, and artificial wetlands. (The video itself only discusses the first.) This article argues that both ion exchange 
and artificial wetlands are better solutions than the one proposed in the video: better ethically, financially, and technically. What is important here is that students can see how abstract engineering and mathematical concepts can be applied to respond to a real world problem.

We cite the Pritchard and Holtsapple paper because it shows how cases in ethics can be modified to teach engineering concepts as well. Integration works both ways. Ethical issues can be integrated into ordinary technical classes, for example, by rewriting homework exercises to include questions that reflect on their ethical implications. ${ }^{4}$ Moreover, engineering concepts can be integrated into ethics cases by thinking carefully about how engineering skill and knowledge can be utilized to design and implement ethical solutions. Ethics cases, when properly written, provide real world contexts in which abstract engineering and mathematical concepts come alive.

Another example shows how mathematical concepts used in engineering can be taught through ethics cases. The NSF/Bovay workshop (August 1995) developed numerical problems associated with ethics cases to show how ethical considerations can be integrated into mathematical and engineering problems. ${ }^{5}$ UPRM students have worked with the Mt. Dioxin case that was developed through this project. This case raises a series of difficult ethical problems. For example, an EPA official is pressured to approve a soil excavation plan before all the data from soil sampling studies has been compiled. The authors also include exercises that employ concepts in engineering and mathematics such as the following: What would be the lift force acting on a vinyl tarp used to cover stockpiled contaminated soil under certain environmental conditions such as high wind velocity? ${ }^{6}$ The ethical issues raised by Mt. Dioxin call for the use of technical knowledge and skill in designing and implementing effective solutions.

The point of both of these examples is that it is not necessary to stop teaching engineering in order to teach ethics; ethics instruction can be accomplished by recog nizing that ethics (in the form of realizing value in the world) represents yet another field for the application of engineering concepts.

3. An EAC program that supplements a freestanding, elective engineering ethics course provides a more promising alternative than a program that relies entirely on a required course in engineering ethics. It responds effectively to ethics requirements but does not overburden students and faculty.

The stand-alone engineering ethics class is an effective way of providing students with an indepth look at ethical theories and techniques for problem solving. (The philosophy section of our humanities department has offered engineering ethics for over 15 years.) But while many universities give courses in engineering ethics, few engineering programs have taken the additional step of requiring engineering ethics for all students (Texas A\&M represents a notable exception $^{7}$ ). In general, programs that rely solely on the stand-alone course run headlong into a series of problems:

- Most engineering curricula are too crowded to add yet another requirement. UPRM, for example, has a five-year undergraduate program in engineering; in many cases, students need at least six years to complete all the required studies.

Proceedings of the 2002 American Society for Engineering Education Annual Conference \& Exposition Copyright $@$ C 2002, American Society for Engineering Education 
- Requiring engineering faculty to teach an engineering ethics course would divert their time and energies from their own research and teaching. It would also divert engineering faculty and resources from other areas of the engineering curriculum under review by ABET. Mo st engineering faculty are already heavily committed in these areas; they would understandably be reluctant to set aside such commitments to respond to the demands of teaching a required freestanding engineering ethics course, however legitimate or important they feel these demands are.

- Many philosophy departments are ill equipped to handle the demand created by a required engineering ethics course. As with engineering faculty, philosophy faculty are already committed to research in their own discipline and to maintaining programs of study such as the philosophy major. Some philosophers have told us that they would be unwilling to sacrifice attention to their own programs to respond to required courses in the so-called service areas such as engineering or business ethics.

EAC offers a promising alternative. It exposes all engineering students to ethical issues and problems without overburdening them. It also engages engineering and non-engineering faculty without forcing them to sacrifice other vital concerns by...

- Exposing students to ethical issues in mainstream engineering courses, as these would arise in real practice. An example: an electrical engineer told us that while teaching control systems he has his students discuss whether pilots could safely land an airplane whose controls had failed.

- Allowing engineering faculty to introduce ethical issues into existing engineering cases and problems without crowding out other course content.

- Complementing the freestanding course in engineering ethics. The freestanding course could then be oriented toward students who are interested in a more intensive exploration of ethical problems. The rest would receive adequate coverage of ethical issues in ordinary engineering courses where these issues would be introduced on a "just-in-time" basis.

\section{EAC gives engineering faculty an active role in ethics integration without requiring that they} become experts in ethical theory.

Rather than outsourcing all the ethics instruction to ethicists, EAC relies heavily on engineering faculty to deal with ethical issues in their own classes, i.e., in ordinary engineering classes. But this does not overburden them because the goal in EAC is relatively modest: to empower ${ }^{8}$ faculty to introduce ethical issues into ordinary technical classes by means of integration exercises. This involves equipping faculty with the ability to recognize ethical issues, lead discussions of ethics cases, develop exercises that combine ethical and engineering concepts, and assess student work on ethics integration exercises. Several universities have designed workshops to address these needs that are feasible, given the time and energy constraints that engineering faculty have. For example, the Illinois Institute of Technology offers a 7-day workshop that prepares faculty in EAC. $^{9}$

In short, EAC can effectively respond to ABET 2000 ethics concerns: (1) it presents students with a better integrated curriculum that shows that ethics is a key component of engineering practice; (2) it makes abstract engineering concepts concrete so it actually can aid in teaching engineering; (3) it represents a viable alternative to a required course in ethics; (4) it actively 
involves faculty in the integration of ethics into the engineering curriculum by empowering them to design and teach ethics integration exercises and modules.

\section{Summary of Workshops and Methodology}

As part of UPRM's preparation for their upcoming ABET accreditation visit, we presented three workshops on ABET and EAC: April 6, 2001 (for members of the ABET College-Wide Committee); May 14, 2001(for professors from industrial engineering); November 30, 2001 (for several other faculty members from engineering).

In designing our workshop, we felt it important to generate materials that engineering faculty could use both in their classes and for documenting results for ABET. Given the time constraints we faced (we have held half-day and full-day workshops), we decided upon having the participants craft short ethics cases or scenarios that could be used in engineering classes.

We began by modeling cases and integration exercises that have been used successfully in the past. First, a member of our team presented an Introductory Ethics Integration Exercise that he has used to introduce ethical issues to students in an Introduction to Computers class. An example taken from this exercise is the following:

An employee uses his or her PC at work to send email to friends and relatives

Do you think that...

a. this situation is common/realistic?

b. this situation is Ethical or Unethical?

c. others might disagree with you?

We presented this scenario to workshop participants without a prior discussion of the nature of engineering ethics, ethical theory, or any decision-making framework. We asked them to take the point of view of their students and respond to the questions that followed the scenario. The discussion, which we allowed to run for about 20 minutes, tended to be lively, but somewhat unfocused. Some comments were ...

"You really need to put more information in this scenario to answer it properly."

"The answer depends on company policy or property law."

"What is the right answer to this dilemma?"

Having awakened their ethical sensitivity, we then presented three ethics tests that we referred to as the "Moral Minimum":

- REVERSIBILITY: Would I think this is a good choice if I were among those affected by it?

- PUBLICITY: Would I want this action published in the newspaper?

- HARM: Does this action do less harm than any available alternatives? 
With the help of these tests, which we associated with different ethical approaches (Deontology, Virtue Ethics, and Utilitarianism respectively), the participants were able to discuss several other scenarios in a more focused and coherent manner.

After a short introduction of $\mathrm{EAC}^{10}$, we presented an exercise used by one of us to introduce ethics to students in mechanical and industrial engineering capstone design courses. It is loosely patterned on the Lockheed/Marietta game, Gray Matters. ${ }^{11}$ (This exercise differs from the Lockheed/Marietta version in that the responses are not scored and the central goal is to practice decision-making rather than teach the ethical values of a particular organization.) We divided the workshop participants into teams of four or five and assigned each team a different scenario. The following is an example of one of the scenarios (other examples are found in Appendix A):

You are an electrical engineer and have been practicing as a professional engineer for five years now. A close friend and cousin of yours has just completed a one year vocational draftsmanship program and comes to you with a proposal. He will develop blueprints for clients at $\$ 75$ dollars a page, and bring you the final version for you to sign off on for anywhere from $\$ 200$ to $\$ 300$ (depending on the complexity). You keep the fee for signing off on the blueprints while he keeps the $\$ 75$ per page fee. What should you do?

a. Don't do it! This would violate canon 2 of the CIAPR's ${ }^{12}$ code of ethics.

b. Don't do it! Even though it doesn't violate canon 2, it violates $5 \mathrm{j}$.

c. Do it. After all, it's common practice and your cousin is perfectly capable of drawing up adequate blueprints. (It's also good for the family, and your uncle would vouch for him.) d. Consult with someone (an official of the CIAPR or one of your former university professors) to see if this would be a violation of the spirit of the engineering code of ethics.

e. Your solution...

Each group was told to read their scenario and the accompanying solutions, discuss them, choose the solution they thought best (or devise one of their own), and prepare a defense of their conclusions in terms of the ethics tests mentioned above. After 20 minutes, we asked each team to present and defend its solution before the rest of the workshop participants.

Both these exercises provided participants with a chance to see short cases that had already been effectively used in the classroom and to visualize a typical ethics integration exercise. We kept our comments to a minimum although we did make some meta-comments during the discussion. (Meta-comments are comments a discussion leader can make to reflect on the discussion itself, e.g., its structure, how it compares with other discussions, the theoretical points it presupposes, and so forth.)

After these two exercise demonstrations, we touched upon some aspects of writing and discussing ethics cases. ${ }^{13}$

- First, we pointed out that cases could be written from a participant point of view (What should you do if you were in this situation?) or an evaluator's point of view (What do you think about what others have done or are about to do in this situation?). Writing a case from the participant point of view provides students with practice on the skills of ethical awareness, ethical evaluation, and integration. Writing a case from the evaluator's point of

Proceedings of the 2002 American Society for Engineering Education Annual Conference \& Exposition Copyright (C) 2002, American Society for Engineering Education 
view would promote evaluative skills and could also touch on ethical awareness and preventive skills.

- Second, we noted that the solutions to the Gray Matters scenarios were constructed around four generic options: (1) go along with the suggested action, (2) oppose it, (3) try to negotiate, or (4) exit, i.e., get yourself out of the situation. Constructing solutions around the four options is a good way of starting the process of brainstorming solutions to ethical problems. We stressed that it was not necessarily the case that the "right" answer was among the solutions proffered, although sometimes the decision actually taken was included.

- Finally, we presented a case that a student group had rewritten, comparing the first version with the second. The first version did not produce much of a discussion (it was written from the evaluator's point of view) but the rewriting was quite successful (it was written from the participant's point of view).

Having made these points, we felt that the participants were ready for their own foray into case writing.

We began this stage by again dividing the participants into teams of four to six and giving each team a template of both integration exercises. Then we asked them to develop three to five short cases dealing with ethical issues that could arise from application of the engineering concepts and skills they teach in their classes. After this, they could take either template (whichever best fit the structure of the case) and generate new integration exercises specifically tailored to their individual classes. After 45 minutes, we reconvened and had each group present its cases and exercises to the rest of the workshop while the audience took on the role of students and offered solutions to the problems raised by the cases. Sometimes they changed roles and asked questions to clarify different aspects of the case and made suggestions on how to improve it.

What we received were rough drafts of several cases. After the workshop we refined these, writing them into the Introductory Ethics Integration Exercise or Gray Matters (or both). In the following, we present an example of this transformation. For example, during our April 6 workshop, a group crafted the following case:

You have your own business, and want to get a contract with town Z. You submit your proposal the first year, but do not get the contract. The second year you are told that a contribution to the mayor's re-election campaign will significantly increase your chances to get the contract. What should you do?

We rewrote the scenario so it would fit into the Introductory Ethics Integration Exercise framework. This requires presenting the scenario as a pattern of behavior and asking whether it is common/realistic, ethical or unethical, and controversial. To fit this format we wrote the following from the evaluator's point of view:

Juan is a recent graduate from UPRM trying to start up his own business in the construction industry. Town $Z$ opens the bidding on a lucrative construction project. When he mentions to Pedro that he is thinking of submitting a bid, Pedro tells him that it will not be successful unless he makes a hefty campaign contribution to the mayor's 
reelection bid. He suggests that Juan inflate his bid to include the campaign contribution and hide this by padding other expenses.

We left out the first unsuccessful bid since it wasn't really essential to stating the practice involved in the scenario (the mayor accepting only bids from those who make campaign contributions). We also converted the case into an evaluation case by writing it from the evaluator's point of view; we switched the voice from second person to third person. Finally, we added the part about inflating the bid to make the case more dramatic.

Next, we rewrote the case to fit the Gray Matters format. This required changing the voice back to the 2 nd person and concluding the case by asking for a decision. After this, we crafted various solution alternatives based, again, on the generic options of going along, opposing, negotiating, and exiting. The result was the following:

You are a recent graduate from UPRM and are trying to start up your own business in the construction industry. Town $Z$ opens the bidding on a lucrative construction project. When you mention to a friend that you are thinking of submitting a bid, he tells you that it will not be successful unless you make a hefty campaign contribution to the mayor's reelection bid. He suggests that you inflate your bid to include the campaign contribution and hide this by padding other budget items. What should you do?

a. Do exactly as your friend says. After all, it is common practice, and you are as entitled to that bid as any other contractor.

b. Submit an honest bid and make no contribution to the mayor's reelection campaign. If this is the way the mayor does business, you want no part of it. Bribery violates your ethical and professional principles.

c. Do as your friend says but just this one time. Once you get your construction firm started you can then operate it with integrity.

d. Blow the whistle on this corrupt mayor. You could go to the local press, a government official, or your professional society.

e. Your solution...

The first two workshops produced four new integration exercises and twenty-two new cases/scenarios. We have included these in Appendix A. We will also post these materials on our web site, www.uprm.edu/ethics. (This web also site includes the instructor's manuals we prepared for these workshops, 50 cases developed through our NSF-funded ethics initiative (SBR-9810253), evaluation forms that could be used to assess these materials, and other useful teaching resources.)

\section{Conclusion}

In this paper, we have discussed several aspects of a series of workshops that we have offered at UPRM on ethics across the curriculum. We began with a discussion of the advantages of an EAC approach for responding to ABET 2000 criteria three and four. Second, we discussed the methodology we used during these workshops to generate teaching materials: new ethics integration exercises (designed for integration ethics into ordinary engineering courses) and new 
cases in engineering ethics. Some of these results are presented in the Appendix. They exemplify an EAC approach to the ABET 2000 ethics requirements. ${ }^{14}$

The next step is to refine and present the EAC program objectives, outcomes, and assessment relevant to engineering in terms of the continual process of improvement which ABET 2000 requires of the entire engineering curriculum. We propose to report on this in a sequel to this paper and in future workshops/presentations.

\section{References and Notes}

${ }^{1}$ Ibo van de Poel (2001) Investigating Ethical Issues in Engineering Design, Science and Engineering Ethics, 7: 429-446.

${ }^{2}$ NSPE stands for the National Society of Professional Engineers.

${ }^{3}$ Michael Pritchard \& Mark Holtzapple (1997) Responsible Engineering: Gilbane Gold Revisited Science and Engineering Ethics 3; 217-230

${ }^{4}$ Michael Davis (1999) Ethics and the University, Routledge, London, 128, 157.

${ }^{5}$ Michael J. Rabins, Edwin Harris Jr., \&Jeremy E. Hanzlik (1996) An NSF /Bovay Endowment Supported Workshop to Develop Numerical Problems Associated with Ethics Caswes for Use in Required Undergraduate Engineering Courses. Proceedings of the 1996 American Society for Engineering Education Annual Conference and Exposition: session 3332. See also http://ethics.tamu.edu/.

${ }^{6}$ C. E. Harris, M. S. Pritchard, \& M. J. Rabins (2000) Engineering Ethics: Concepts and Cases. Wadsworth, Belmont. See the CD-ROM, Cases, Mt. Dioxin. Edmund Tsang and John Reis developed this case.

${ }^{7}$ Michael J. Rabins (1998) Teaching Engineering Ethics to Undergraduates. Science and Engineering Ethics 4: 2991-301.

${ }^{8}$ José Cruz \& William J. Frey (2001) Ethical Empowerment: An Ethics Module for Introduction to Computers. Proceedings of the 2001 American Society for Engineering Education Annual Conference and Exposition: Session 1520.

${ }^{9}$ The IIT workshop is described in detail by Michael Davis (1999) Ethics and the University, Routledge, London, Chapter 7. On the other hand, some universities (for example, St. Olaf) employ intensive, summer-long workshops that amount to graduate level courses in ethical theory. But their goal is more ambitious: to empower faculty to develop and teach stand-alone ethics courses in their areas of expertise.

${ }^{10}$ We have discussed many of the ideas in this introduction in the previous section of this paper. For further discussion see, José A. Cruz and William J. Frey (2001) An Effective Strategy for Integrating Ethics Across the Curriculum in Engineering: An ABET 2000 Challenge (Unpublished manuscript).

${ }^{11}$ Caroline Whitbeck (1998) Ethics in Engineering Practice and Research Cambridge University Press, Cambridge/New York, 176-181.

${ }^{12}$ CIAPR stands for the Colegio de Ingenieros y Agrimensores de Puerto Rico, the College of Engineers and Surveyors of Puerto Rico. Canon 2 prohibits working outside one's area of expertise while Canon 5, practical norm $\mathrm{j}$ prohibits a PE from signing off on documents that he or she has not properly inspected.

${ }_{13}$ Michael Davis (1999) Ethics and the University, Routledge, London, 143-174. Here, Davis provides a comprehensive discussion of the case method parts of which we used in our workshop and in the instructor's manuals we prepared for participants.

${ }^{14}$ We recently had an opportunity to discuss our workshop with engineering ethics faculty from several universities when we gave a panel presentation before the Association for Practical and Professional Ethics on March 2, 2002. What this audience found most useful was not the idea of ethics across the curriculum (we counted seven presentations on EAC during the conference, not including our own) but the results from our workshops that we reported: the cases developed and the success of the workshop in awakening the interest of our engineering faculty for trying out ethics integration exercises in their classes. Whatever approach an engineering college uses to respond to ABET ethics requirements, we feel that support from the engineering faculty is crucial. Our workshop has proven a good means for generating this support.

Proceedings of the 2002 American Society for Engineering Education Annual Conference \& Exposition Copyright $\odot$ 2002, American Society for Engineering Education 


\section{Biographical Information}

\section{JOSÉ A. CRUZ}

José A. Cruz has a degree in Computer Engineering and a Ph.D. in Intelligent Business Systems. Presently he is an Associate Professor of Information Systems in the College of Business Administration at the University of Puerto Rico at Mayagüez. He has worked for the last few years with Dr. Frey and Dr. Sanchez offering workshops in Ethics Across the Curriculum and has presented on the topic at various international conferences.

\section{WILLIAM J. FREY}

William J. Frey is a Professor of Philosophy at the University of Puerto Rico at Mayagüez. He is the associate Director of the Center for Philosophy in its Interdisciplinary Function, an ethics center affiliated with UPRM. He is working with Dr. Cruz and Dr. Sanchez on various UPR Central Administration initiatives to promote Ethics Across the Curriculum in the university system.

HALLEY D. SANCHEZ

A former Dean of the College of Arts and Sciences, Halley D. Sanchez is presently a Professor of Philosophy and Adjunct Professor of Physics at the University of Puerto Rico at Mayagüez. He is also an associate in the Center for Philosophy in its Interdisciplinary Function, an ethics center affiliated with UPRM 


\title{
Appendix A
}

\section{Ethics Integration Exercise Demonstration By José A. Cruz-Cruz, UPR-Mayagüez (Scenarios from EAC Workshop, May 14, 2001)}

\section{Step 1: Individually evaluate the scenarios below using the following three questions:}

\author{
For each of the scenarios below react to the following three questions:

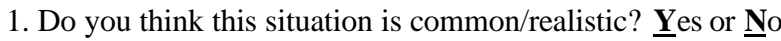 \\ 2. Do you think this situation or activity is $\underline{\mathbf{E}}$ thical or $\underline{\mathbf{U}}$ ethical? \\ 3. Do you think others might disagree with you (Question \#2)? $\underline{\text { Yes or }}$ No
}

A. An advanced undergraduate course in Enginering Economics (a course that has both graduate and undergraduate students) requires a group project that comprises $40 \%$ of their grade.

In the self-evaluation one group submitted with their project, 4 of the students (all graduate students) claim that a fifth (an undergraduate) did not do any work. The undergraduate, on the other hand, claims that he tried to work but was excluded from the group project because he was an undergraduate.

B. The engineering manager has presented a recommendation for an office re-layout. A central part of this plan involves moving several hourly employees under your supervision to a new site. You are concerned because the employees will have to travel between the new and old sites to perform certain functions, and the resulting increased transportation time costs were not included in the analysis. The re-layout starts today.

C. A professor submitted an article in a scientific journal and did not include the name of the student who wrote the computer program that produced results central to the article. When the article was published and the student saw that his contribution was not mentioned, he called the professor and insulted him for not including him as coauthor. D. A student shows up to attend a review session for the "reválda", the official examination for licensure in engineering. Before entering he meets a professor who has recently resigned from the department. This professor offers the student the chance to attend another review session that he is directing at a lower cost.

E. The president of an engineering association has publicly stated that a department in a well-known school of engineering does not offer courses in a certain area of engineering when in fact it does under a different course name. What should the department do?

F. An engineer working for a large multinational company discovers, upon studying several procurement contracts, that a key supplier is bribing somebody in the higher echelons (top management or board of directors). If he goes public with this situation, he will jeopardize his job.

G. A supervisor discovers that a public employee is illegally pocketing rent money from government properties. The supervisor turned over the evidence to the Department of Justice. However, the district attorney failed to attend the preliminary hearings for the trial, and the charges were dismissed.

Some time later, this supervisor discovered that another employee was doing the same thing. Angry that the first employee got away with his illegal act, he approached the second employee and told him that he had a certified legal statement to the effect that the employee was robbing state funds. He demanded that the employee resign immediately or he would make this information public. The employee resigned. However, the supervisor had no such legal document. He was merely bluffing.

H. Engineer Juan del Pueblo has been called as an expert witness in a case in criminal court. Although he could give a quasi-technical presentation to convince the jury that the defendant is innocent, he knows that his presentation would not be precise enough to establish guilt or innocence beyond doubt. 
Step 2: Informally share or discuss your answers with the class. Use the space below to make notes:

Step 3: Ethical Decision Making Guidelines: Four(informal) tests:

REVERSIBILITY: Would I think this is a good choice if I were among those affected by it?

PUBLICITY: Would I want this action published in the newspaper?

HARM: Does this action do less harm than any available alternatives?

FEASIBILITY: Can this solution be implemented given time, technical, economic, legal, and political constraints?

Step 4: Divide into groups re-evaluate the remaining scenarios using the above tests, then share or discuss your group's answers with the class. Use the space below to make notes.

\begin{tabular}{|c|l|l|l|l|}
\hline Scenario & Reversibility & Publicity & Harm & Feasibility \\
\hline $\begin{array}{c}\text { A } \\
\text { (the excluded } \\
\text { undergraduate) }\end{array}$ & & & & \\
\hline $\begin{array}{c}\text { B } \\
\text { (the office re- } \\
\text { layout) }\end{array}$ & & & & \\
\hline $\begin{array}{c}\text { C } \\
\text { the } \\
\text { unmentioned } \\
\text { student) }\end{array}$ & & & & \\
\hline $\begin{array}{c}\text { D } \\
\text { (the cheaper } \\
\text { review session) }\end{array}$ & & & & \\
\hline $\begin{array}{c}\text { E } \\
\text { (false public } \\
\text { declarations) }\end{array}$ & & & & \\
\hline $\begin{array}{c}\text { F } \\
\text { (bribery) }\end{array}$ & & & & \\
\hline $\begin{array}{c}\text { G } \\
\text { (bluffing for a } \\
\text { good cause) }\end{array}$ & & & & \\
\hline $\begin{array}{c}\text { H } \\
\text { (the expert } \\
\text { witness) }\end{array}$ & & & & \\
\hline
\end{tabular}




\title{
Decision-Making in Engineering By William J. Frey \\ Center for Philosophy in its Interdisciplinary Function \\ (Cases from EAC Workshop, April 6, 2001)
}

\begin{abstract}
Directions: Read the following scenarios and the accompanying solutions. Evaluate the alternatives in terms of the following tests. Choose the one you think best or design your own solution.
\end{abstract}

REVERSIBILITY: Would I think this is a good choice if I were among those affected by it?

PUBLICITY: Would I want this action published in the newspaper?

HARM: Does this action do less harm than any available alternatives?

CODE TEST: Does the solution alternative carry out or violate any code provisions?

FEASIBILITY: Can this solution be implemented given time, technical, economic, legal, and political constraints?

\section{Scenarios:}

1. Juan is a software engineer who has just started working for company ABC. His first assignment is to redesign a software program in less than a month. He can think of only one way to do this: download a library and integrate it into the program. But to make a legal down load, the company must first pay $\$ 10,000$ to the manufacturer. This is a gamble; if the library cannot be integrated into the program, ABC doesn't get its money back. Furthermore, it will take more than a month to purchase it from the manufacturer. What should Juan do?

a. Illegally down load the library, integrate it into the program, and test it. If it passes the test, then Juan can recommend to $\mathrm{ABC}$ that it pay the manufacturer the $\$ 10,000$.

b. Go to his supervisor at $\mathrm{ABC}$ and ask for more time to redesign the software.

c. Recommend to $\mathrm{ABC}$ that they pay the manufacturer $\$ 10,000$ even though they will not get a refund should the software fail the test. He could also enlist ABC's help in pushing the manufacturer to make the library available in less then the usual time.

d. Look for another job. He'll get ulcers if ABC keeps imposing unrealistic deadlines on him.

e. Your solution...

2. You are a recent graduate from UPRM and are trying to start up your own business in the construction industry. Town $Z$ opens the bidding on a lucrative construction project. When you mention to a friend that you are thinking of submitting a bid, he tells you that it will not be successful unless you make a hefty campaign contribution to the mayor's reelection bid. He suggests that you inflate your bid to include the campaign contribution and hide this by padding other budget items. What should you do?

a. Do exactly as your friend says. After all, it is common practice, and you are as entitled to that bid as any other contractor.

b. Submit an honest bid and make no contribution to the mayor's reelection campaign. If this is the way the mayor does business, you want no part of it. Bribery violates your ethical and professional principles.

c. Do as your friend says but just this one time. Once you get your construction firm started you can then operate it with integrity.

d. Blow the whistle on this corrupt mayor. You could go to the local press, a government official, or your professional society.

e. Your solution...

3. An engineer is charged with evaluating the risks of severe flooding and mudslides for a small, isolated community located in the central region of Puerto Rico. The results, in her opinion, require that she recommend that the community be relocated. But she also knows that community members will likely object. Many families have lived there for several generations and would not like abandoning the home of their ancestors. Furthermore, they value their solitude and choose to live in this place because it is peaceful and free from the influences of city life. What should she do?

a. Stick to her guns. Her job is to evaluate impartially and scientifically the risks of floods and mudslides to this community, not to get mixed up in a complex social debate. Consequently, if the risks are great enough, devotion to public health and safety mandate that she recommend relocating the community.

Proceedings of the 2002 American Society for Engineering Education Annual Conference \& Exposition Copyright (C) 2002, American Society for Engineering Education 
b. The engineer should look for other alternatives than relocation. For example, could the community be protected from flooding by building a system of levees and catch basins?

c. The engineer should widen the focus of her study to include the social and cultural issues that are of concern to the members of the community. When writing her report she should make clear the risks to the community, but also include such social factors as the commitment of the community members to their family histories and their tranquil way of life.

d. The engineer should recommend holding public hearings to acquaint community with the risks she has studied. During this hearing she should offer the citizens options other than just waiting for floods or relocating the community.

e. She should resign from her work before she becomes swept up in a political turmoil.

f. Your solution...

4. Maria Sanchez is in her final year of engineering at UPRM. These past years have been most difficult financially, and she has had to work at a variety of jobs to cover her tuition and living expenses. Furthermore, her family is looking to her to help them cover their own financial obligations; her father is sick and has not been able to work for the past year and they stand to lose their home if she is not able to find a stable engineering job when she graduates.

She is taking her last required course to graduate and is convinced that she will fail the final exam. (She was unable to study because of demands from work and other classes.) Maria's friend, a computer science major, tells her that he has found a way to hack into the University's computer system and could access the files in which student grades are located. He offers to change her grade to an A. What should she do?

a. She should accept his offer. Even though she dislikes cheating, she should do so to help out her family.

b. She should go to the professor, explain her situation, and ask to retake the exam,

c. She should accept whatever grade she gets and, if necessary, retake the course.

d. She should quit her job so she'll have more time to study.

e. Your solution...

5. Marta Acevedo, an engineering student, has a laboratory exercise due tomorrow. She has been overwhelmed for the last few weeks with assignments from other classes and doesn't really have time to complete this exercise. She discovers that her roommate took this same class the previous semester and has the complete exercise on disk. What should she do?

a. She should ask her roommate to give her the disk and let her use the exercise she prepared for the previous semester. Her roommate has an obligation to help a fellow student in need. And it is well known that engineering classes are too demanding for the average students.

b. She should go to the professor (preferably with other students in a similar situation) and ask for more time to complete the assignment.

c. She should redouble her efforts and work harder. In this way maybe she'll get the assignment done.

d. Your solution...

6. Julio has been working for the civil engineering firm of Pedro for nearly five years now. He began while still a student and has continued after his graduation. Pedro has been like a father to Julio, teaching him about civil engineering and introducing him to valuable clients. But the pay is poor. Julio has asked Pedro several times for more money but it has not been forthcoming.

Julio has been thinking for some time about starting his own firm. He has made valuable contacts while working with Pedro and is sure that he would have enough clients to do a good business. But he is concerned about the propriety of taking clients away from Pedro. What should he do?

a. Go on ahead and start his own firm. He has given Pedro five years of hard work and has paid his dues.

b. Talk the matter over with Pedro. If he objects, then Julio should abandon his plans of starting up his own firm.

c. Go ahead and start his own firm. But if he gets a contract from one of Pedro's clients, he should subcontract some of the work to his former employer.

d. Start his own firm but refuse to accept business from any of Pedro's clients.

e. Your solution...

Proceedings of the 2002 American Society for Engineering Education Annual Conference \& Exposition Copyright $($ ) 2002, American Society for Engineering Education 